\title{
Rapid Detection of Staphylococcal Enterotoxin-B by Lateral Flow Assay
}

\author{
Robert Hnasko, Alice V. Lin,, and Jeffery A. McGarvey²
}

A cohort of monoclonal antibodies (mAbs) were generated against Staphylococcal enterotoxin-B (SEB) and selected by double sandwich enzyme-linked immunosorbent assay (ELISA) for solution capture of the toxin. Clonal hybridoma cell lines were established and a pair of anti-SEB mAbs selected for the development of a sandwich ELISA. Immobilized 3D6 mAb (IgG1, kappa) when paired with 4C9 mAb (IgG1, kappa) conjugated to horseradish peroxidase generates a typical dose-response curve with an $\mathrm{EC}_{50}$ of $24.8 \mathrm{ng} / \mathrm{mL}$ for purified SEB using chemiluminescent detection. These mAbs bind SEB by Western blot and ELISA binding to classical enterotoxin serotypes show that the 3D6 mAb binds both SEB and the SEC1 serotypes, whereas 4C9 binds only SEB. These mAbs effectively port onto lateral flow test strips with a visual detection sensitivity for SEB of $5 \mathrm{ng} / \mathrm{mL}$ in $<10$ minutes using a $4 \mathrm{C} 9$ conjugated to a $40 \mathrm{~nm}$ gold reporter.

Keywords: monoclonal antibodies (mAb), Staphylococcus aureus, Staphylococcal enterotoxin-B (SEB), lateral flow assay

\section{Introduction}

$S$ TAPHYLOCOCCUS AUREUS IS a pathogenic gram-positive bacterium that can produce an impressive collection of protein toxins. ${ }^{(1-3)}$ These secreted toxins represent virulence factors and staphylococcal foodborne poisoning (SFP) is a leading cause of foodborne illness in the United States. ${ }^{(4-6)}$ The gastrointestinal (GI) illness associated with SFP is rarely life threatening and the disease is usually self-resolving without hospitalization. ${ }^{(7)}$ However, the economic cost and lost productivity associated with SFP warrants effective control strategies. ${ }^{(8)}$

The staphylococcal enterotoxins (SE) represent a large group of structurally similar and serologically distinct proteins $(22-29 \mathrm{kDa})$ encoded in prophages, plasmids, and chromosomal pathogenicity islands. ${ }^{(5,9)}$ There are five classical antigenic types (A-E) and these superantigens elicit an immune response that results in the massive production of inflammatory cytokines. ${ }^{(10-12)}$ SEB is considered the most dangerous as it is produced by most Staphylococcus aureus strains. ${ }^{(7,13,14)}$ SEB is a primary cause of SFP after ingestion $^{(15,16)}$ and is considered a military incapacitating agent as it is highly toxic, thermally stable, and can cause intoxication by inhalation if aerosolized. ${ }^{(17,18)}$
SEB intoxication is difficult to distinguish from other GI illnesses and there is no vaccine and has limited treatment options. ${ }^{(13)}$ There are many immunoanalytical technologies available for SEB detection, but a need remains for portable, rapid, and inexpensive methodologies to address foodborne contamination. ${ }^{19,20)}$ Commercially produced lateral flow test strips in general report $5-10 \mathrm{ng} / \mathrm{mL}$ detection sensitivities using optical readers ${ }^{(21,22)}$ and their applicability is primarily directed toward emergency first responders. In this article we report the generation of a novel cohort of anti-SEB monoclonal antibodies (mAbs) and identify a suitable pair for the development of a sandwich enzyme-linked immunosorbent assay (ELISA) with application in a lateral flow assay format.

\section{Materials and Methods}

\section{SEB $m A b s$}

Female Balb/cByJ mice (Jackson Laboratory, ME) were immunized by intramuscular injection of an SEB toxoid derived from purified SEB toxin (Sigma, MO) mixed 1:1 with TiterMax gold adjuvant (Sigma). Hybridomas were generated by chemical fusion with P3X myeloma cells and screened by double sandwich ELISA against purified native

\footnotetext{
${ }^{1}$ USDA-ARS Produce Safety and Microbiology Research Unit (PSM), Albany, California.

${ }^{2}$ USDA-ARS Foodborne Toxin Detection and Prevention Research Unit (FTDP), Albany, California.

(C) Robert Hnasko et al. 2019; Published by Mary Ann Liebert, Inc. This Open Access article is distributed under the terms of the Creative Commons License (http://creativecommons.org/licenses/by/4.0), which permits unrestricted use, distribution, and reproduction in any medium, provided the original work is properly cited.
} 
Table 1. The 3D6 and 4C9 Anti-Staphylococcal Enterotoxin-B Monoclonal Antibodies Were Paired for Development of a SAndwich EnZyme-Linked Immunosorbent Assay and Construction of Lateral Flow Test Strips

\begin{tabular}{lllll}
\hline Mouse no. & $m A b$ & Format & Isotype \\
\hline 223 & 3D6 & Capture & IgG1, kappa & Ascites \\
224 & $4 \mathrm{C} 9$ & Detector & IgG1, kappa & Yes \\
\hline
\end{tabular}

These mAbs were further evaluated by indirect ELISA against the staphylococcal enterotoxins A-E with the 3D6 mAb binding SEB and SEC1 and the 4C9 mAb binding only SEB.

ELISA, enzyme-linked immunosorbent assay; mAb, monoclonal antibody; SEB, Staphylococcal enterotoxin-B.
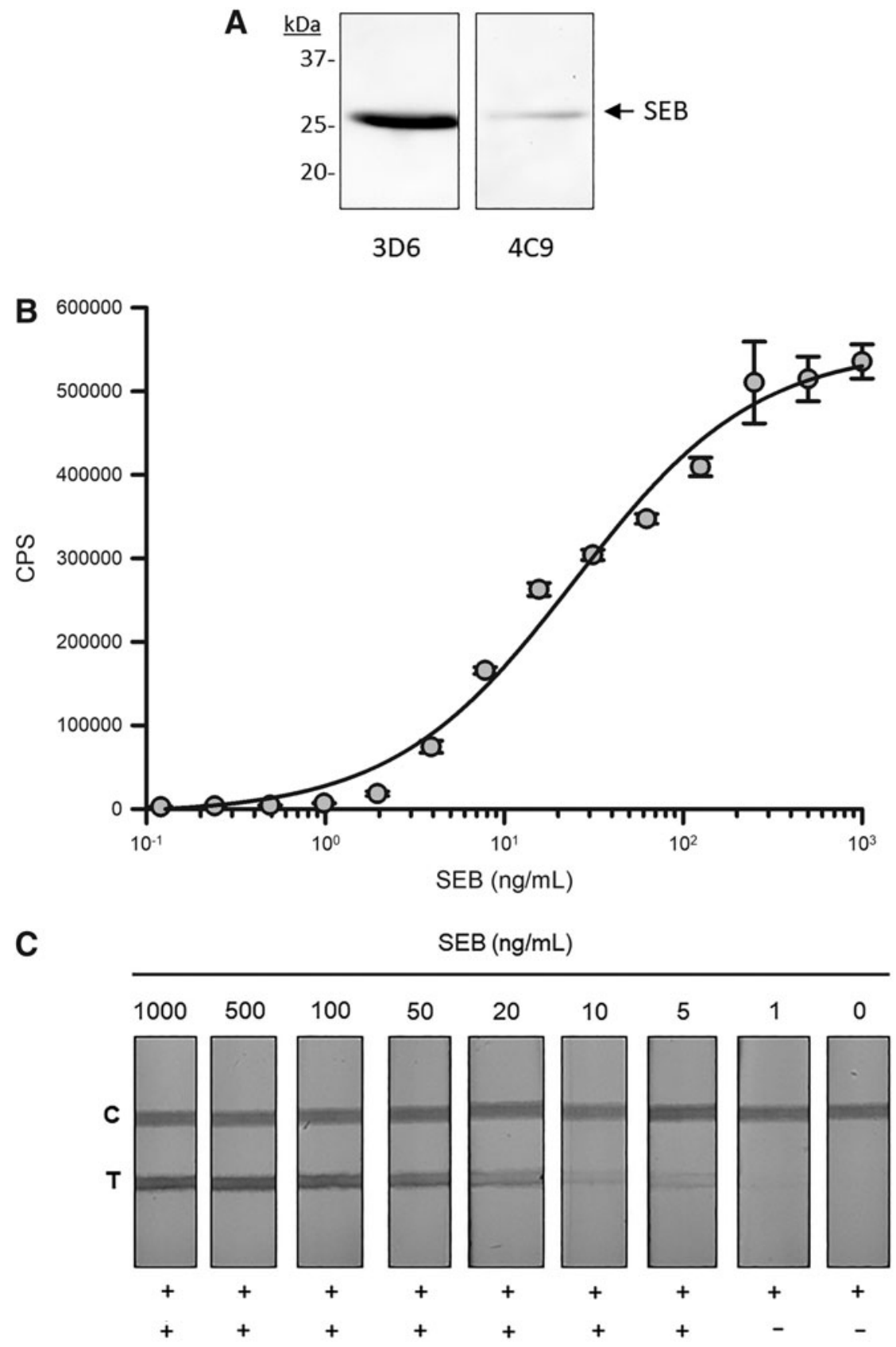

FIG. 1. The detection of $28 \mathrm{kDa}$ SEB by Western blot (A) using the $3 \mathrm{D} 6 \mathrm{mAb}$ (left panel) and $4 \mathrm{C} 9 \mathrm{mAb}$ (right panel). The dose-dependent detection of SEB by chemiluminescent sandwich ELISA (B) using immobilized 3D6 mAb for capture and 4C9HRP for detection. The line represents 4PL dynamic curve fitting of data with an $\mathrm{EC}_{50}=24.8 \mathrm{ng} / \mathrm{mL}$ SEB and $0.85 \mathrm{hillslope}$. Detection of SEB by lateral flow assay (C). SEB is visually detected $(+)$ at the test line (T) using immobilized 3D6 mAb with 4C9 $\mathrm{mAb}$ conjugated to $40 \mathrm{~nm}$ gold. The test line shows a dose-dependent change in visible test line intensity with $5 \mathrm{ng} / \mathrm{mL}$ as the tests limit of detection. A donkey-anti-mouse IgG is immobilized at control line (C) and validates test performance. No test line is observed in the absence of SEB (-). 4PL, four parameter logistic; ELISA, enzyme-linked immunosorbent assay; HRP, horseradish peroxidase; mAb, monoclonal antibody; SEB, Staphylococcal enterotoxin-B. 
SEB (Toxin Technology, FL) using a biotinylated rabbit-aSEB pAb (Toxin Technology) with an avidin-horseradish peroxidase (HRP) reporter and chemiluminescent detection. Hybridoma cell cloning was performed by limiting dilution and total of 24 hybridoma cell lines producing anti-SEB $\mathrm{mAbs}$ were isolated. All animal experiments were performed with institutional approval and followed national guidelines for the care and use of laboratory animals.

\section{Sandwich ELISA}

Anti-SEB mAbs were purified on protein-G and a functional pair of anti-SEB mAbs was identified for the development of a sandwich ELISA. In brief, the capture $\mathrm{mAb}$ (3D6; IgG1, kappa) was immobilized at $2 \mu \mathrm{g} / \mathrm{mL}$ on black 96well high-binding polystyrene plates at $5 \mu \mathrm{g} / \mathrm{mL}$ in $0.1 \mathrm{M}$ carbonate buffer ( $\mathrm{pH}$ 9.4); washed repeatedly in Trisbuffered saline with $0.1 \%$ Tween-20 (TBST; pH 7.2) and blocked in $10 \%$ nonfat dry milk (NFDM). The SEB antigen was diluted in TBST containing 0.1\% BSA and added to wells for 1 hour. The detection mAb (4C9; IgG1, kappa) conjugated to HRP was added at $1 \mu \mathrm{g} / \mathrm{mL}$ for 1 hour. Chemiluminescent substrate (PicoECL; Pierce) was added and luminescent signal recorded as counts per second using a Victor $\mathrm{X}^{3}$ luminometer (PerkinElmer). All reactions were performed at room temperature with a minimum of three replicates. Analysis was performed using four parameter logistic (4PL) with dynamic curve fitting $\left(\mathrm{EC}_{50}=24.8 \mathrm{ng} / \mathrm{mL}\right.$; Hillslope $=0.85$ ).

\section{Western blotting}

The SEB antigen was diluted in sample buffer, heat denatured, and $0.5 \mu \mathrm{g}$ separated on a 4-12\% Bis-Tris Gel and protein transferred to a nitrocellulose membrane. Membranes were washed in TBST, blocked with 10\% NFDM, incubated with $1 \mu \mathrm{g} / \mathrm{mL}$ of primary antibody then secondary anti-mouse IgG conjugated to HRP. Antibody binding was resolved by chemiluminescence and Tiff images captured using a FluroChem HD2 (Alpha Innotech, CA). Molecular weight was estimated using prestained dual-color protein standards (BioRad, CA).

\section{Lateral test strips}

In brief, RP membrane (Millipore) was striped using a noncontact BioJet HR value with a high-resolution syringe pump attached to an XYZ3050 platform (BioDot, CA) with the 3D6 capture $\mathrm{mAb}$ as a test line $(\mathrm{T})$ and a donkey-antimouse IgG used for the control line (C). The RP membranes were water washed, then blocked in polyvinylpyrrolidone (PVP40; Sigma) and dried. The 4C9 $\mathrm{mAb}$ was conjugated to $40 \mathrm{~nm}$ gold (InnovaCoat Gold; Innova Biosciences) and 10 OD sprayed onto a $10 \mathrm{~mm}$ glass fiber conjugate pad (Millipore) using a noncontact AirJet HR aerosol dispenser (BioDot) attached to the XYZ platform. Dried membranes were adhered to $60 \mathrm{~mm}$ plastic backing card with $25 \mathrm{~mm}$ Fusion-5 membrane (GE Healthcare) as a sample pad and $22 \mathrm{~mm}$ CF6 membrane (Millipore) as an absorbent sink. The test strips were cut $(60 \times 4.5 \mathrm{~mm})$ and housed in a two-part plastic cassette with a pressure point at material overlap. Dilutions of SEB were added to the sample pad $(100 \mu \mathrm{L})$ and resolved for 10 minutes and then photographed.

\section{Results and Discussion}

We have isolated and cloned 24 anti-SEB producing hybridoma cell lines by double sandwich ELISA. Our screening and selection assay utilized purified SEB in its native conformation emphasizing solution capture capability of the mAbs. Most of these mAb show a high degree of SEB binding selectivity and perform in a variety of immunoassay formats that include sandwich ELISA, direct ELISA, Western blotting and lateral flow. Some of these mAbs evaluated by ELISA against the classic SEs (A-E) show binding to the SEC1 serotype that shares the most amino acid sequence identity $(68 \%)$ with the SEB protein. ${ }^{(23)}$

A pair of anti-SEB mAbs (3D6 and 4C9), with IgG1 heavy chains and kappa light chains, was identified for assay development (Table 1). The 3D6 mAb binds both SEB and SEC1, whereas the 4C9 mAb binds only SEB in ELISA (data not shown). These mAbs bind purified heat denatured SEB protein by Western blot (Fig. 1A). To develop the sandwich ELISA the 3D6 mAb was immobilized and used for SEB capture with the $4 \mathrm{C} 9 \mathrm{mAb}$ used for detection. A typical doseresponse curve was observed using purified SEB dilutions with an $\mathrm{EC}_{50}$ of $24.8 \mathrm{ng} / \mathrm{mL}$ of SEB and a hillslope of 0.85 using 4PL dynamic curve fitting (Fig. 1B). These two $\mathrm{mAb}$ both function in the sandwich ELISA format as either a SEB capture or detection reagent (data not shown).

To develop a rapid SEB detection assay these mAbs were ported on standard $60 \times 4.5 \mathrm{~mm}$ lateral flow test strips with the 3D6 mAb immobilized at a test line (T) and $40 \mathrm{~nm}$ goldconjugated 4C9 as a SEB reporter. A donkey-anti-mouse IgG was immobilized at the control line (C) and functions to validate the proper performance of the test strip. A dilution series of purified SEB was prepared, $100 \mu \mathrm{L}$ was applied to the test strip sample pad, and the test allowed to resolve for 10 minutes and then photographed. Visually observable test lines indicating detection of SEB were observed down to $5 \mathrm{ng} / \mathrm{mL}$ (Fig. 1C). No test line was observed in the absence of the SEB analyte.

Although the 3D6 mAb will bind the SEC1 serotype, when paired with the selective $4 \mathrm{C} 9 \mathrm{mAb}$ the assay will only detect the SEB serotype. This serotype specificity would address concerns regarding SE cross-reactivity reported with some commercial assays. ${ }^{(24)}$ Many commercially available SEB lateral flow assays fail to report the sensitivity of their tests, whereas other require optical readers to achieve $5-10 \mathrm{ng} / \mathrm{mL}$ SEB detection. In this article we report a lateral flow assay that achieves $5 \mathrm{ng} / \mathrm{mL}$ SEB detection sensitivity by visual observation. Further optimization of these SEB-specific reagents in a lateral flow assay format along with the integration of an optical reader will likely result in an increase in detection sensitivity and assay performance suitable for commercialization.

\section{Author Disclosure Statement}

No competing financial interests exist.

\section{Funding Information}

This research was supported by USDA-ARS National Program in Food Safety (\#2030-42000-050). The USDA is an equal opportunity provider and employer. 


\section{References}

1. Benkerroum N: Staphylococcal enterotoxins and enterotoxinlike toxins with special reference to dairy products: An overview. Crit Rev Food Sci Nutr 2018;58:1943-1970.

2. Pinchuk IV, Beswick EJ, and Reyes VE: Staphylococcal enterotoxins. Toxins (Basel) 2010;2:2177-2197.

3. Krakauer T, and Stiles BG: The staphylococcal enterotoxin (SE) family: SEB and siblings. Virulence 2013;4:759-773.

4. Schelin J, Wallin-Carlquist N, Cohn MT, Lindqvist R, Barker GC, and Radstrom P: The formation of Staphylococcus aureus enterotoxin in food environments and advances in risk assessment. Virulence 2011;2:580-592.

5. Argudin MA, Mendoza MC, and Rodicio MR: Food poisoning and Staphylococcus aureus enterotoxins. Toxins (Basel) 2010;2:1751-1773.

6. Kadariya J, Smith TC, and Thapaliya D: Staphylococcus aureus and staphylococcal food-borne disease: An ongoing challenge in public health. Biomed Res Int 2014;2014: 827965.

7. Fisher EL, Otto M, and Cheung GYC: Basis of virulence in enterotoxin-mediated Staphylococcal food poisoning. Front Microbiol 2018;9:436.

8. Scharff RL: Economic burden from health losses due to foodborne illness in the United States. J Food Prot 2012;75: $123-131$.

9. Hennekinne JA, Ostyn A, Guillier F, Herbin S, Prufer AL, and Dragacci S: How should staphylococcal food poisoning outbreaks be characterized? Toxins (Basel) 2010;2:2106-2116.

10. Krakauer T: Staphylococcal superantigens: Pyrogenic toxins induce toxic shock. Toxins (Basel) 2019;11:E178.

11. Stach CS, Herrera A, and Schlievert PM: Staphylococcal superantigens interact with multiple host receptors to cause serious diseases. Immunol Res 2014;59:177-181.

12. Proft T, and Fraser JD: Bacterial superantigens. Clin Exp Immunol 2003;133:299-306.

13. Fries BC, and Varshney AK: Bacterial toxinsStaphylococcal enterotoxin B. Microbiol Spectr 2013;1-2.

14. Zhang Y, Wang Y, Cai R, Shi L, Li C, and Yan H: Prevalence of enterotoxin genes in Staphylococcus aureus isolates from pork production. Foodborne Pathog Dis 2018; 15:437-443.

15. Schelin J, Susilo YB, and Johler S: Expression of Staphylococcal enterotoxins under stress encountered during food production and preservation. Toxins (Basel) 2017;9:E401.

16. Hennekinne JA, De Buyser ML, and Dragacci S: Staphylococcus aureus and its food poisoning toxins: Character- ization and outbreak investigation. FEMS Microbiol Rev 2012;36:815-836.

17. Janik E, Ceremuga M, Saluk-Bijak J, and Bijak M: Biological toxins as the potential tools for bioterrorism. Int $\mathbf{J}$ Mol Sci 2019;20:E1181.

18. Zapor M, and Fishbain JT: Aerosolized biologic toxins as agents of warfare and terrorism. Respir Care Clin N Am 2004;10:111-122.

19. Wu S, Duan N, Gu H, Hao L, Ye H, Gong W, and Wang Z: A review of the methods for detection of Staphylococcus aureus enterotoxins. Toxins (Basel) 2016;8:E176.

20. Chiao DJ, Wey JJ, Tsui PY, Lin FG, and Shyu RH: Comparison of LFA with PCR and RPLA in detecting SEB from isolated clinical strains of Staphylococcus aureus and its application in food samples. Food Chem 2013;141: 1789-1795.

21. Boyle T, Njoroge JM, Jones RL, Jr., and Principato M: Detection of staphylococcal enterotoxin B in milk and milk products using immunodiagnostic lateral flow devices. J AOAC Int 2010;93:569-575.

22. Gholamzad M, Khatami MR, Ghassemi S, Vaise Malekshahi Z, and Shooshtari MB: Detection of Staphylococcus enterotoxin B (SEB) using an immunochromatographic test strip. Jundishapur J Microbiol 2015;8:e26793.

23. Jarraud S, Peyrat MA, Lim A, Tristan A, Bes M, Mougel C, Etienne J, Vandenesch F, Bonneville M, and Lina G: Egc, a highly prevalent operon of enterotoxin gene, forms a putative nursery of superantigens in Staphylococcus aureus. J Immunol 2001;166:669-677.

24. Tallent SM, Hait J, and Bennett RW: Staphylococcal enterotoxin B-specific electrochemiluminescence and lateral flow device assays cross-react with staphylococcal enterotoxin D. J AOAC Int 2014;97:862-867.

Address correspondence to: Robert Hnasko USDA-ARS Produce Safety and Microbiology Research Unit (PSM) 800 Buchanan Street Albany, CA 94710

E-mail: robert.hnasko@ars.usda.gov

Received: June 20, 2019 Accepted: August 28, 2019 